\title{
Social Media Usage in Albanian Market
}

Erlis Çela, PhD. Cand.

Phd. Candidate, "Hëna e Plotë" Bedër University,

ecela@beder.edu.al

\begin{abstract}
In nowadays we see a large use of social media in every aspect of the life. Social media personal usage, social media in terms of information (news), social media in elections and of course a large use of this definition is seen also in marketing. Social media is considered as a new medium in two way communication where people can share their experiences and where they can communicate with other people. It is very dynamic comparing to traditional media. What is published now and may be up-to-date today can be disappeared from the virtual environment tomorrow. The interactivity, the share/retweet effect have created the opportunity of reaching to more and more people. Corporations have become aware of these opportunities and also that all eyes were focused on social media for this reason they had to be adapted very quickly to this environment. Nowadays it is very difficult to find any company which does not have at least an account in Facebook. Most of the companies with the aim to reach to more people have created their profiles/pages in all social media platforms. This new development has forced the companies and marketing professionals to direct their market communication strategies also in the social media. The appearance of the new medium and the development in the communication technology has brought huge transformation even in the marketing science.
\end{abstract}

Keywords: Social Media, Social Media Marketing, Companies, Facebook, eWOM (electronic word of Mouth)

\section{Research Objectives and methodology}

Social media is one of the most listened term in nowadays life. We face social media in news sector in advertising management etc. and we may accept that this new media has fundamentally changed the way how we communicate with each other, how media communicates with audiences, how politicians communicate with voters, how companies communicate with consumers.

Consumers in the new media called "social media" it is likely that they may not only find information useful directly from the company's social account but also form other consumers and the two sources of information (and persuasion) could potentially reinforce (or weaken) each other. (Hiroshi Onishi, Puneet Manchanda, 2012, p. 226). Social Media is considered also a game changer since people communicate with each other and they may change the way of communication by sharing their experiences therefore the company may become from the "most liked" in the "most hated" company" e.g American Airlines due to the publication of the experience of its customer incidentally, was designated as 'most hated' on social media according to a research done by Amplicate in October, 2011. (Parihar, 2012, p. 4)

In such a technology development medium the communication is developed in an electronic environment, and is becoming very dynamic and very uncontrolled, where any personal negative impression or experience can be posted in a social account wall or blog the companies are facing with a new media they have to manage for marketing itself.

In this paper will be refer to the usage of this type of media by big companies in Albania. First of all we will go through the definition of social media in terms of marketing and corporate communication and usage in the world. By referring to the previous studies and literature review we will try to give a framework regarding the usage of social media in marketing campaigns, and reasons why social media is being used by companies and marketing professionals.

The objective of this study is to understand the status of social media usage in the Albanian market.

In this paper we will try to give answer to the questions 
a) Why companies use the Social Media?

b) How social media has influenced the relation of the companies with their consumer?

These questions in fact are the core discussions in every study of Social Media Marketing

Regarding the Social Media marketing situation in Albania we will search for answers to the questions: Do companies in Albania use social media marketing and in which platforms they own an account. Reason why they are using, frequencies of publication? Are companies in Albania designing social media usage strategies and what is the $\%$ of budget they spend for Social Media Marketing.

Data is collected from several secondary sources like journal articles, research papers, websites and online social media portals. Regarding Albania Market usage situation there is given attention to the primary research as:

- Direct Interviews directed to the Marketing representatives of some big companies in Albania

- Monitoring of Facebook Accounts of 7 organization as companies, banks and universities for two months.

\section{Literature Review}

\subsection{What is Social Media?}

The launching of social networks like Facebook, Google+, Twitter, YouTube and many other platforms changed the way of communication. Starting from the e-mails, passing to the social networks where people can share an experience a status a personal generated content and many others could read in the same time would move the communication to another dimension. As of January 2009, the online social networking application Facebook registered more than 175 million active users. At the same time, every minute, 10 hours of content were uploaded to the video sharing platform YouTube. Forrester Research transmits that in $2008,75 \%$ of Internet surfers used "Social Media" by joining social networks, reading blogs, or contributing reviews to shopping sites and this value represents a significant rise from 56\% in 2007 .

Based on the determinations of Web 2.0 and UGC (User Generated Content) the Social Media definition can be classifies as a group of Internet-based applications that build on the ideological and technological foundations of Web 2.0, and that allow the creation and exchange of User Generated Content. (Kaplan \& Haenlein, 2010, p. 61).

Social Media is considered as New Media. Boyd and Ellison in 2008 would define social networking sites web based services that allow individuals to:

- Construct a public or semi-public profile within a bounded system

- Articulate a list of other users with whom they share a connection and

- View and traverse their list of connections and those made by others within this system.

The social media functioning follows the above logic therefore social media is defined as any technological communication that utilizes peer-to-peer networking as its primary dissemination form. (Hamilton, 2011, p. 4)

Social media platforms have understood that consuming content, and forming relationships around it by discussing, sharing and reacting to it, are parts of the same experience. According to Parihar social media supports the human need for social interaction with technology, transforming broadcast media monologues (one to many) into social media dialogues (many to many). This new type of medium has changed the way how people communicate with each other, how they take the information regarding their friends, their service providers, products etc.

\subsection{What is Social Media Marketing?}

The development of this new kind of communication, has created to the customers the opportunity to be empowered to reach out to millions of other customers in a matter of seconds and this has drastically changed the way in which they can 
share their experiences about products and services - and the way in which companies can respond (if at all) to such information (Parihar, 2012, p. 3).

Social media marketing, or SMM, is a form of internet marketing that implements various social media networks in order to achieve marketing communication and branding goals. Social media marketing primarily covers activities involving social sharing of content, videos, and images for marketing purposes (TS, 2014).

According to Tracy Tutten and Michael Solomon, Social media marketing is considered as the utilization of social media technologies, channels, and software to create, communicate, deliver, and exchange offerings that have value for an organization's stakeholders. We can see this definition play out in emerging trends in social media. While social media marketing initially influenced brands' promotional plans, more recent business applications include social funding and social indexing. (Tutten, Solomon, 2014, p. 21)

Based on the classifications of Social Media Marketing, companies are facing with a new goal: to produce content that users can share in their social networks in order to increase brand awareness and so increase their sales.

Social media helps companies to get direct feedback from customers and new potential customers and to the customers give the opportunity to ask questions or raise complaint regarding a product/ service. The customer relationship can be kept also through social media platforms.

Thanks to the development of social media channels, people can learn about a product or service through reviews, blogs or groups, and decide whether or not to use that product or service. Then, organizations are no longer the ones in power at the moment of controlling information about their products in the social media world. It is important to understand that there are still companies who need to work on strategies for embracing social media for communication (McCorkindale, 2010 , p. 4). Social Media is the new medium which can be used by marketing professionals in order to communicate their marketing.

\subsection{Why Companies use Social Media?}

Above we mentioned that Social Media is a new medium and the companies, marketing institutions can use. Considering the velocity of spreading of the information social media can be a very good tool to communicate the marketing, to share information regarding the product, offers etc. But why they use and shall use this new media. Below by having a look to the literature we will try to find the reasons why social media is being used by the companies.

According to Mirko Gati and Eva Markos Kujbus ${ }^{1}$ Social Media is very interactive and users can share information with others on it very easily. This new interactive media platform gives the opportunity of developing marketing communication strategies. The transformation from one way communication model to a more complex two way model is a direct effect of the democratization of information, where not only companies talk to their customers but customers talk directly to each other (Eva Markos Kujbus, Mirko Gati, 2012, p. 5). With New Media the companies have the opportunity to listen and talk with their customers, receive feedback and giving support to the customers for their products and services.

Nowadays companies operating in every sector have created their social networks profiles. Today's biggest brands have the largest social online communities and these are managed by dedicating valuable resources to ensure that the relationship between the brand and its community becomes and remains strong. (Parihar, 2012, p. 10).

Another reason why companies use social media is because the access to information is open "The social feedback cycle is important to understand because it forms the basis of the social business. What the social feedback loop really represents is the way in which internet-based publishing and social technology has connected people around business or business like activities. This new social connectivity applies between a business and its customers (B2C), between other businesses (B2B), between customers themselves". (Evans, 2010, p. 5). Social media gives to the companies the opportunity to reach more consumers in the place where they work they live without waiting them to be sit in front of a TV, also customers has

\footnotetext{
${ }^{1}$ Mirko Gati and Eva Markos Kujbus -Institute of Marketing and Media Budapest
} 
the opportunity to express directly in a quick way their needs to the marketers. The quick feedback creates to the opportunity to react quick and meet customers' needs.

People feel it necessary to communicate with other people their experiences regarding any product or service, which is performed very easily through social media. The "word of mouth concept" is being adapted very good in virtual word. Taking into consideration that the Word of mouth marketing is the intentional influencing of consumer-to-consumer (Robert Kozinets, Kristine De Valck, Andrea C. Wojnicki and Sarah J.S., 2009, p. 3) companies aim to implement this strategy through social media. The Internet's accessibility, reach and transparency have empowered marketers interested in influencing and monitoring WOM as never before. Product reviews shared through social media are read also by other people and this fact is considered as electronic word of mouth. Considering this situation companies are confronted with another challenge, which is to produce a content which does not stimulates any negative review.

The cost of social media marketing versus traditional marketing can be one of the reasons that the companies are adopting quickly to the social media marketing. Keith Queensberry states that Today, businesses are relying less on buying audiences with paid ads in traditional mass media and are turning to marketing on social media. (Quesenberry, 2015). Kaplan and Haentein (2010) and Bonnes (2010) state that for firms the use of Social Media is a low cost investment that can have higher levels of efficiency comparing to traditional media.

Social Media can be very a very effective tool in helping companies to reach the business goals. Through social media interactivity the companies have the opportunity to receive feedback about its products/services from the customers and to receive new customers considering the electronic Word of Mouth. (Franceska Cezaroni, Domeniko Consoli, 2015, p. 66).

One of the major reasons for using social media is managing effectively the Customer Relationships. Business owners are becoming more interested in increasingly interested in using social media to optimize their customer experience management activities because they know social media is changing the CRM game (Parihar, 2012, p. 12).

Donna L. Hoffman and Tomas Novak in the Why people use Social media state "In the "connect-consume" goal pair, the primary focus of the interaction is on connecting with other people and the primary direction of the interaction is on consuming content. Goals in this connect-consume quadrant involve individuals consuming user-generated content created by others (Me ↔ Other People)". If we consider "Me" as a company and "Other people" as consumers we agree that one of the major reasons why companies use Social Media is receiving feedback and putting an interactive relation with consumers.

If we monitor the results of the researched done over usage of social media we can agree that one of the reasons is reaching to more and more users. Even some criticizers state that social media is just another 'fad' the following statistics can confirm the opposite.

- It took radio 38 years to reach 50 million users. TV took 13 years; internet took 4 years, Apple iPod took 3 years to reach the same number of users but Facebook, achieved over 200 million users in less than a year!

- If Facebook were a country, it would be the third largest after China and India.

- $80 \%$ of companies use social media for recruitment, especially Linkedln

- $50 \%$ of mobile internet traffic in the US is for Facebook

- YouTube has become the second largest search engine in the world after Google

- Wikipedia - the open source online encyclopedia, has over 15 million articles.

- Surprisingly, $78 \%$ of these articles are non-English.

- More than 1700 new articles are added on Wikipedia every hour! etc.

Over these facts social media cannot be a "fad" (Parihar, 2012). Social media has become an important part of daily communication. For this reason the companies in order to reach to more customers has adopted the new media.

Are companies using this new medium? According to Social Media Examiners Report yes. Michael A. Stelzener in 2015 Report states that $96 \%$ of the asked people use social media to market their businesses. They indicated they are participating in social media marketing. And $92 \%$ of marketers said that social media was important to their businesses. (Stelzner, 2015). For the case of Albania we will see the statistics in section Albanian Market Context. 


\section{Albanian Market Context}

\subsection{Are Albanian companies using social Media?}

Social Media in marketing communication is born together with the born of Social Networks named social media. Alongside with big companies such as telecommunication companies, banks the usage of social media is seen in every sector like retail businesses as textile shops or universities. In order to understand the social media marketing usage in Albania is the interview received from the Marketing Communication Directors of the respective company. The questions directed to marketing communication professionals are listed as below:

1. Do you use Social Media Marketing techniques in your marketing communications?

2. In which of the Media Platforms you have accounts. (Ex, Facebook, Twitter)

3. For what purpose do you use this platforms

4. In what frequency you publish content in social media account (ex. advertisements)

5. How you manage Social Media Accounts? Do you have a specific position in the company dealing with this?

6. Do you design a special strategy for usage of social media marketing?

7. At what percentage of marketing communication budget is Social Media Marketing Budget ( in Percentage)

The questions were directed to 3 telecommunication companies and two banks representatives. We could receive answers only from two telecommunication companies and two banks, respectively Albtelecom ${ }^{1}$, Telecom Albania ${ }^{2}$, BKT (National Commercial Bank) ${ }^{3}$ and Raiffeisen Bank ${ }^{4}$. To the question if they use Social Media Marketing techniques in their marketing communications they state that they are active in social media platforms.

Regarding the media platforms that they have accounts Albtelecom marketing communication representative states that they manage accounts in Facebook, Instagram, YouTube social media platforms (Marcom, 2015) ${ }^{5}$ while Telecom Albania owns accounts in Facebook, Twitter, YouTube, Linkedln (Ndrecka, 2015), BKT Facebook, Linkedln, Twitter, Google+, YouTube (Bunguri, 2015), while Marketing communication representative from Raiffeisen Bank stated that the platforms in which they manage accounts are Facebook, Twitter, Linkedln, Youtube. When it comes to the reason why they use the above platforms Ndrecka states: "we publish every new product or service. also social activities, cultural and art events that we support".

Albtelecom representative confirms that they use mostly for the advertisement of products, new offers, promotions etc. BKT uses the social media platforms "to establish a two-way, instant and more proactive communication. Also to reinforce the perception of BKT as a mature yet innovative brand" (Bunguri, 2015) while Raiffeisen Bank uses social media to advertise new products and services, to communicate with actual and/or new clients (Raiffeisen, 2015). Regarding the publishing content/ posting frequency Ndrecka confirms that mostly in Facebook they publish the new offers, products, services the day they are launched.

In addition, Telecom Albania publishes at least one post per day. In the other accounts, they publish each time there is a news. Posting frequency is at least once per week. Albtelecom representative states that they publish almost every day, every time they have to communicate to the customers something new. Since telecommunication companies are very dynamic the posting frequency is mostly daily. This fact is also stated by the monitoring of Facebook accounts for this two companies and Vodafone.

\footnotetext{
1 The ALBtelecom Company, which was created in 1912, right after the Independence of Albania and was licensed to provide fixed telephony and internet services by the Entity of Telecommunications Regulation (ERT) in 1992. ALBtelecom is owned by CETEL a.s. in Ankara (76 percent of the shares), and by the Albanian Government and other shareholders (24 percent). It offers fixed telephony and broadband internet services, IPTV services and mobile services under Eagle Mobile brand part of Albtelecom. (Albtelecom, n.d.)

2 Telecom Albania is the new brand of Albanian Mobile Telecommunication (AMC)-Brand is changed on 23rd July 2015. Telecom Albania offers Mobile services and is the first company that has offered mobile telephony services.

${ }^{3}$ BKT (National Commercial Bank) is the largest and the oldest commercial bank in Tirana, Albania. (BKT, 2015)

${ }^{4}$ Raiffeisen Bank Albania is one of the largest bank in the country. Its asset base is close to 2 billion Euro. Raiffeisen Bank International purchased the Albanian Savings Bank in 2004 (Raiffeisen Bank, n.d.)

${ }^{5}$ Marcom- Marketing Communication Representative of Albtelecom- Note: Both representatives from Albtelecom and Raiffeisen Bank preferred to remain anonymous.
} 
While banks publish BKT- Up to 10 times per week on average and Raiffeisen Bank does not have a specific time and frequency of publishing. Regarding any specific position that manage this accounts Telecom Albania, BKT and Raiffeisen Bank confirm that they have a dedicated person only for social media marketing in their structure, while BKT takes support from the digital advertising company. Albtelecom has a team of 5 persons starting from Brand Manager, Designer, Web Developer and a person dealing with the communication. To the question if they develop any strategy for usage of social media Marketing the companies representatives answered respectively Telecom Albania that they designs such strategy (Ndrecka, 2015), BKT states that the strategy of online presence is an important part of the overall communication strategy (Bunguri, 2015), Raiffeisen Bank builds strategy for social media as communication channel (Raiffeisen, 2015), whereas Albtelecom does not builds strategy for social media. They just try to compensate the budgetary deficiencies in the mass media marketing and work with the social platforms without affecting big budget. (Marcom, 2015). The question At what percentage of marketing communication budget is Social Media Marketing Budget (in Percentage) was answered only by BKT and Albtelecom which declares that the budget of social media is $5 \%$ because the majority of the budget goes to the Mass Media marketing, Promotional campaigns and printing materials. In the social media they try to spend minimally and only when it is seen as a must (Marcom, 2015), whereas BKT declares that budget is $7-10 \%$ of the overall budget. Two other companies answered as No info and Confidential.

In 2013 a survey organized among US companies Chief Marketing Officers (www.cmsurvey.org) reported that the total social media marketing was at the range of $8.4 \%$ of the total marketing budget and it was about to increase at $22 \%$ in the next five upcoming years (Dkyun Lee, Kartik Hosanagar, Harikesh S.Nair, 2014). In the question asked to the Marketing Communication Representatives of the companies in Albania the answers varied from $5 \%-10 \%$ of the overall budget. Considering this fact the social media marketing usage in Albania is still not in the level of western countries where even two years later it remains in the same range of 2013 year usage in USA.

\subsection{Albanian Companies Facebook Accounts Monitoring}

For a better understanding of the social media marketing usage it is addressed to the monitoring of some companies Facebook accounts. Evidences from monitoring of Facebook accounts is seen that companies publish informative content where it enters advertisement, information of prices, launch of offers etc. and content which is more social like "where are you going for weekend" "this weekend let's visit Berat", "Let's remember our childhood" organization of events etc., content which is classified as customer engagement content. This type of content gives the message that the company cares about customers. In this type of posts it is seen an increase of the likes and shares and as a result customer becomes more engaged toward the company.

During observation is taken in the consideration what kind of content is published, how frequently is published, likes, comments and shares.

The companies Facebook accounts are monitored for two month. Under Monitoring Process were 3 Telecommunication companies, 2 Banks and 2 Universities. The table shows the Facebook usage statistics. In the section below the will be shown the figures divided by operation sector.

\begin{tabular}{|c|c|c|c|c|c|c|c|c|}
\hline \multicolumn{9}{|c|}{ FACEBOOK MONITORING STATISTICS } \\
\hline & \multirow[t]{2}{*}{ Company } & \multirow[t]{2}{*}{$\begin{array}{l}\text { Page } \\
\text { Likes }\end{array}$} & \multirow[t]{2}{*}{ Postings } & \multicolumn{2}{|l|}{ Posting Types } & \multirow[t]{2}{*}{ Likes } & \multirow[t]{2}{*}{ Comments } & \multirow[t]{2}{*}{ Shares } \\
\hline No & & & & Advertisement & Engagement & & & \\
\hline 1 & Vodafone & 589000 & 46 & 24 & 22 & 70692 & 2249 & 1035 \\
\hline 2 & Telecom Albania & 561000 & 50 & 24 & 26 & 21107 & 798 & 366 \\
\hline 3 & Albtelecom & 163000 & 38 & 12 & 26 & 6967 & 375 & 666 \\
\hline
\end{tabular}




\begin{tabular}{|c|c|c|c|c|c|c|c|c|}
\hline 4 & BKT & 60000 & 22 & 10 & 12 & 7243 & 68 & 96 \\
\hline 5 & Raiffeisen Bank & 24000 & 13 & 9 & 4 & 268 & 3 & 6 \\
\hline 6 & Epoka University & 62000 & 28 & 28 & & 2005 & 7 & 118 \\
\hline 7 & $\begin{array}{l}\text { Tirana European } \\
\text { University }\end{array}$ & 33000 & 10 & 10 & & 360 & 4 & 9 \\
\hline
\end{tabular}

Table 5- Albanian Market Facebook Usage Statistics

\subsubsection{Telecommunication Companies Facebook Monitoring Statistics}

The companies, Vodafone, Albtelecom and Telecom Albania were monitoring during June-July 2015

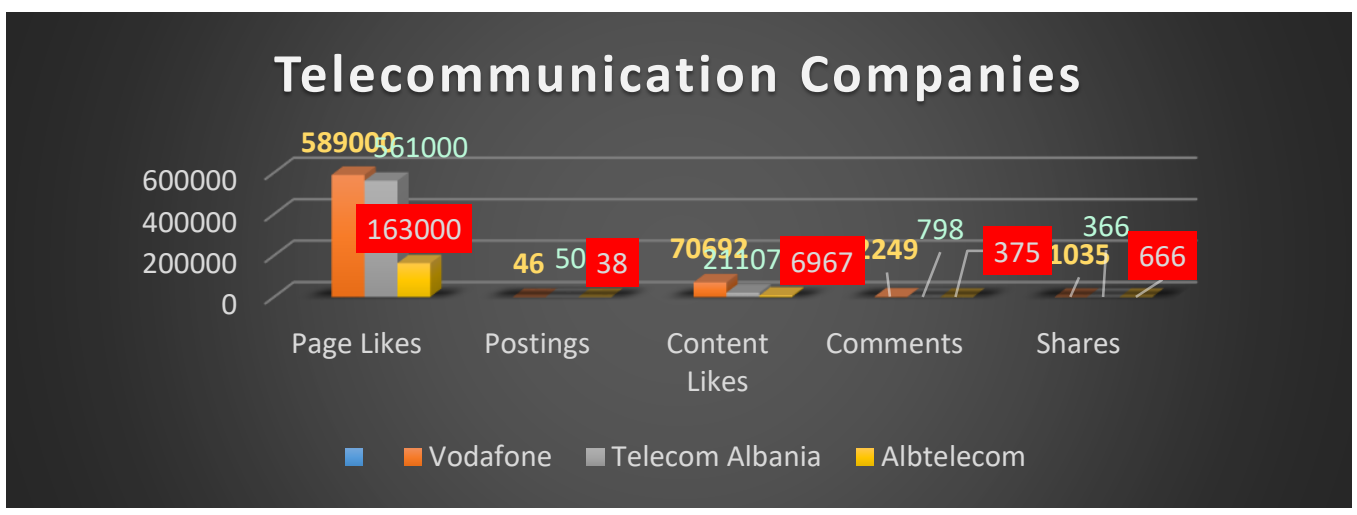

Figure 1- Telecommunication Companies Facebook Usage

Considering the annual ranking of the companies in regards of earnings done by Monitor Magazine a financial periodical, Vodafone is one of the biggest companies in Albania. If we look over the Facebook statistics we see that Vodafone is the company that has the largest likes, comments and shares for posting. Having this fact into count we may confirm that social media has achieved its aim in field of marketing. More clicking, more satisfied customers, more earnings for the company.

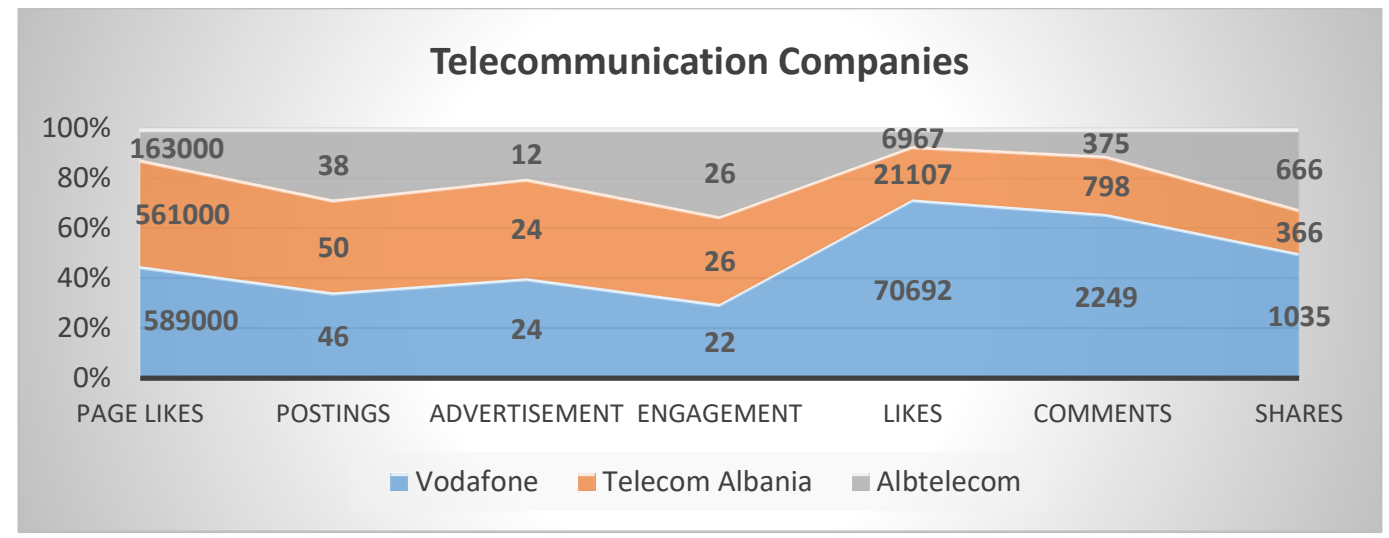

Figure 2-Telecommunication Companies Facebook Monitoring Statistics 
The below graph shows the averages likes, shares and comments done per posting during two months that the companies Facebook accounts have been monitoring. As seen by the graphic Vodafone has the greatest likes, shares and comments per post. Even this period AMC (Telecom Albania) launched its new name and have a publishing activity more often than normal days.

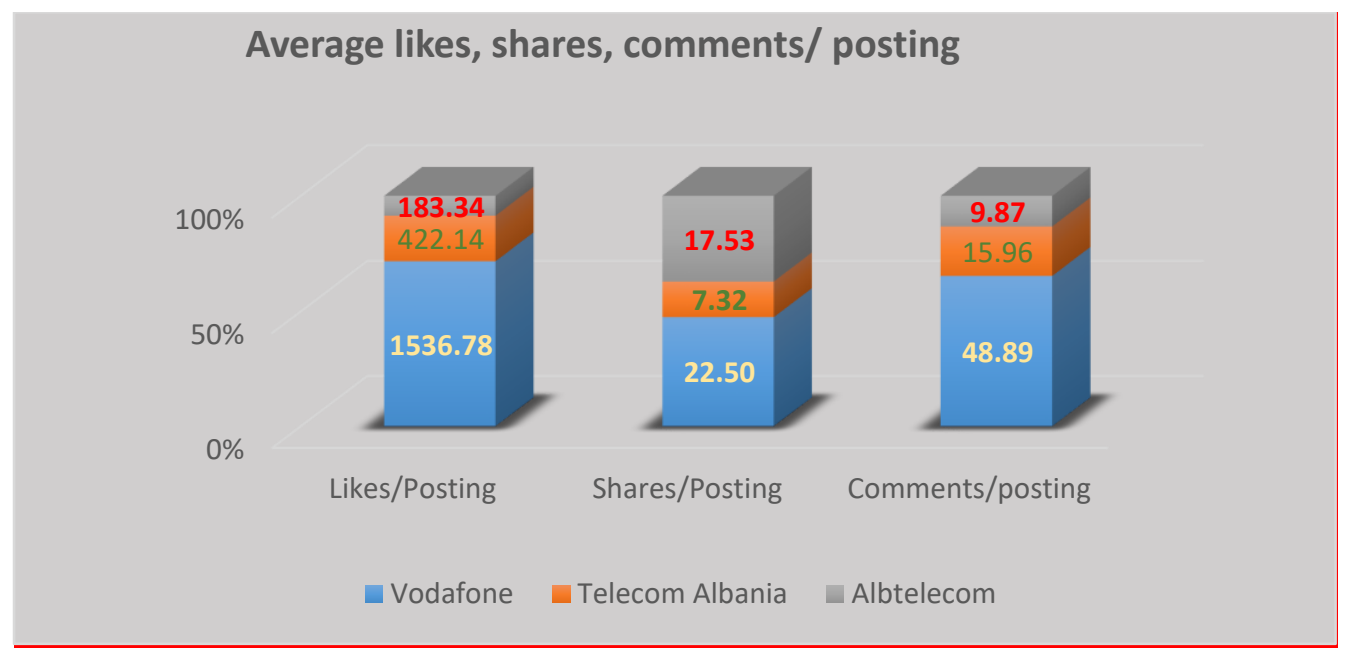

Figure 2-Graph of Average Likes, shares, comments per post

\subsubsection{Banks Facebook Usage}

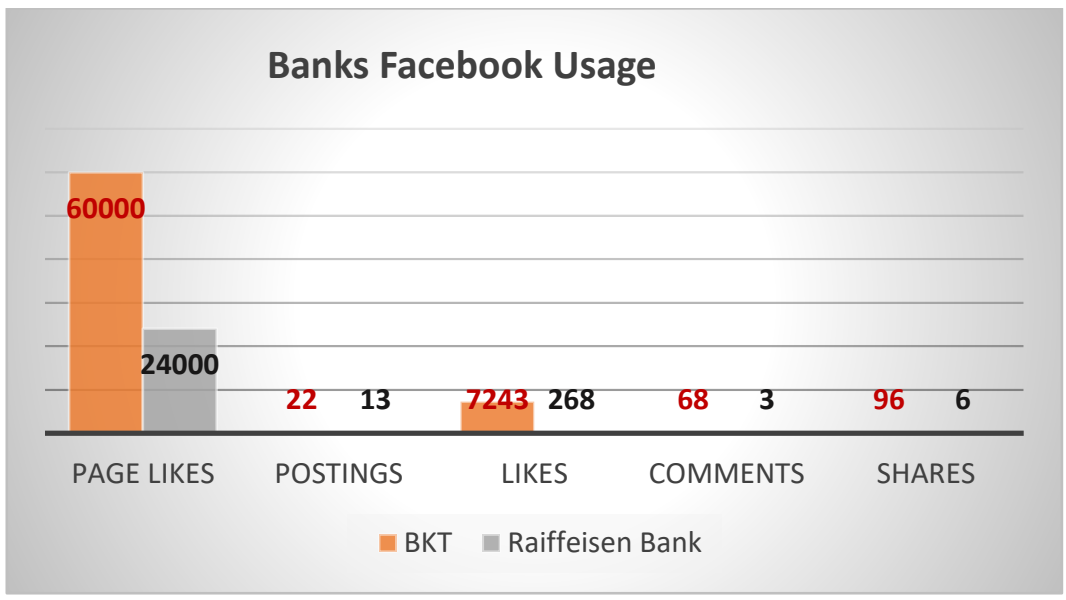

Figure 3-Banks Facebook Usage

Banking sector is not very dynamic regarding to the interactivity in the social media. This is noted by the number of the postings which for BKT is 22 postings during a two months period and for Raiffeisen is 13 postings. This is confirmed also by their representatives intervied where it was mentioned that for Bkt the publishing numbers arrives up to 10 per week. If we see the number 22 during one week it is postied 2-3 times a number which confirmes not to be very present into social 
media. Whereas the representative from Raifeissen didn't specified any frequency of posting. Raiffeisen Bank is one of the biggest and has more customers than BKT however it has less page likes than BKT. The below graphic shows some statistics regading the average of likes shares and comments done per posting.

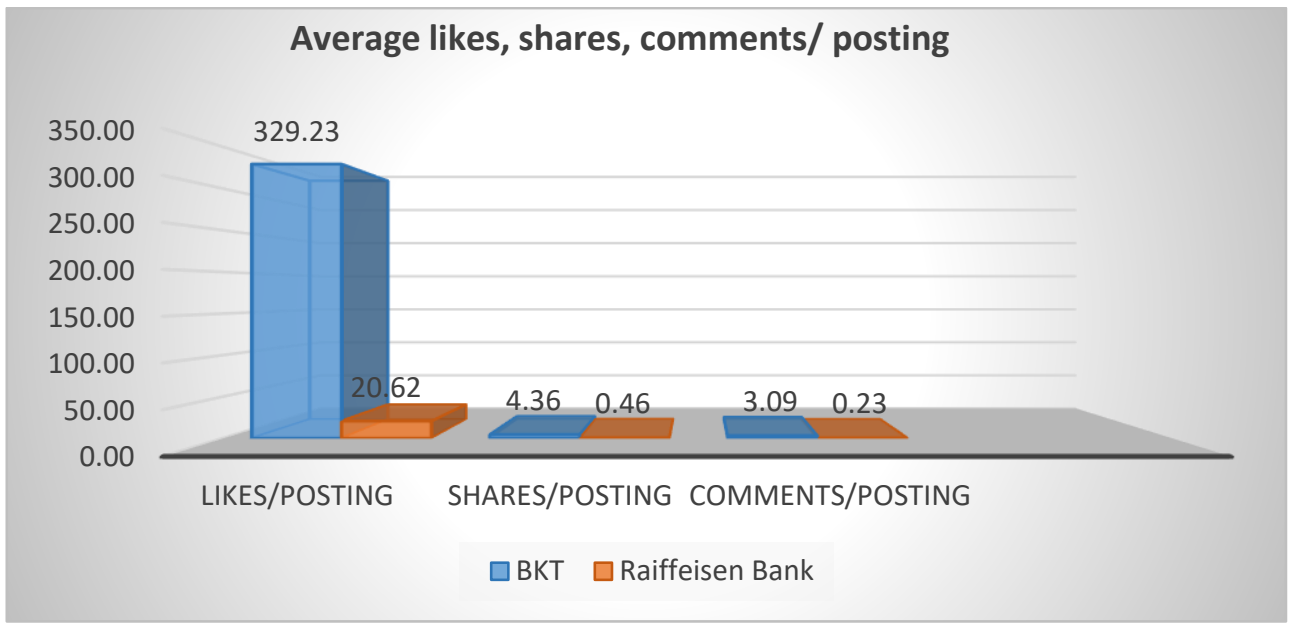

Figure 4-Graph of Average Likes, shares, comments per post (Banks)

If we refer to the banking evaluations Euromoney has evaluated for the fourth year (from 2011 to July 2015) and the best Bank in Albania and it is not the only. Other financial institutiosn have evaluated BKT as the best bank in Albania. (BKT, 2015). It is obvious that the presence and the interactivity in social media with more likes per page per posting, more shares more comments is related with the quality of the service and the sattisfied customers.

\subsubsection{Universities Facebook Monitoring Statiscs}

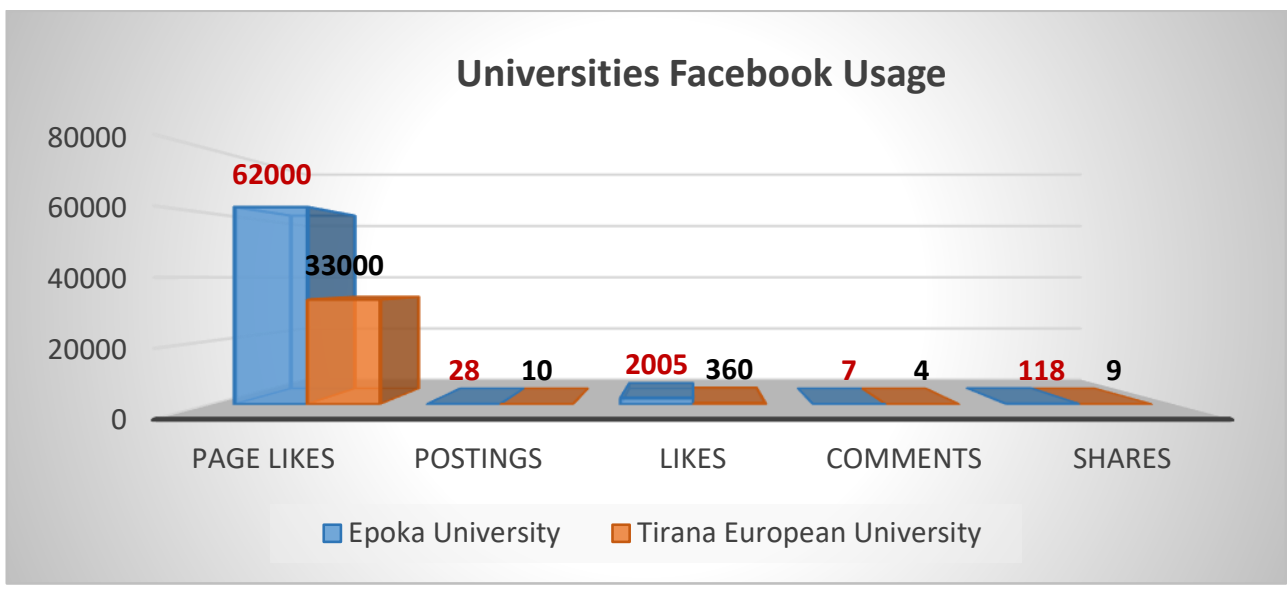

Figure 5-Universities Facebook Usage 
Two private universities were monitored during May-July 2015 Epoka University ${ }^{1}$ and Europian Univesity of Tirana (UET)2. Taking into the consideration the monitoring statistics it is obvious that universities are at the last place regarding the usage of social media comparing to other sectors. Before the monitoring

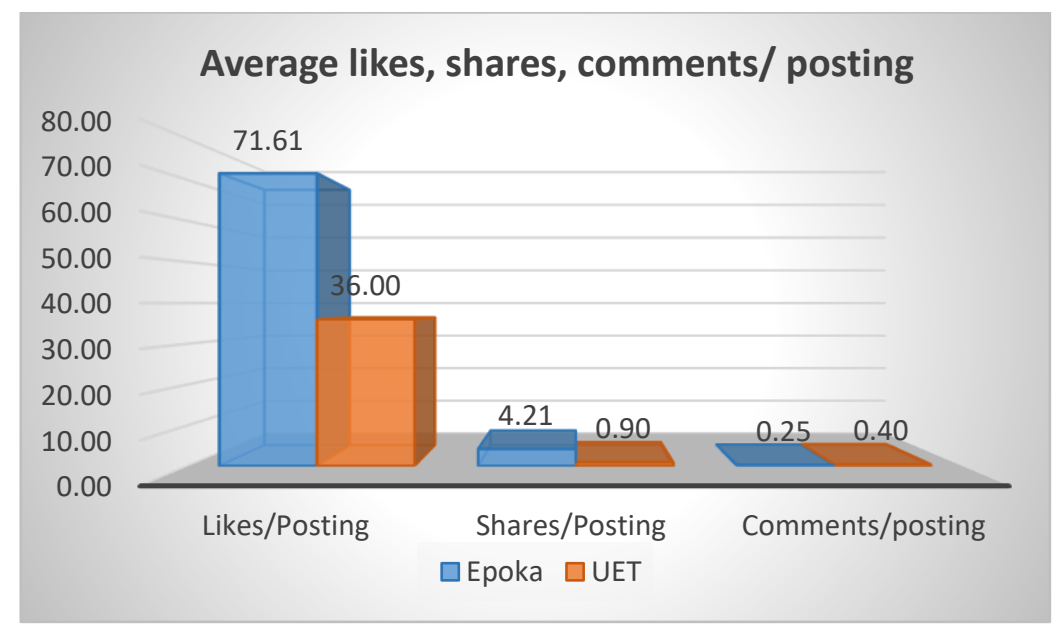

Figure 6-Graph of Average Likes, shares, comments per post (Universities)

We had the opinion that universities have students as a population and are very young and their accounts would be very active. However it was the opposite. This may be related to the period which corresponds to the end of academic year or to the issue that it has a different product to which is offered only to a specific population. If we do a comparison with each other Epoka University has the biggest page likes and the likes shares and comments per

posting. It is obvious that in this sector also the interactivity of social media usage is related to the quality of service/ product as a result to the satisfied customer* (Students). Epoka University is ranked as best private university in Albania and second after Tirana University (Public University). (Webometrics, 2015)

\section{Conclusion and suggestions}

Social media as the new medium is widely used in Marketing field. Businesses and marketing professionals have inserted this new medium in their marketing communication strategies. Different authors and also evidences from the Albanian market research confirm that the reason why companies use social media is interactivity of social media and opportunity to receive quick feedback. The quick feedback is important to understand the customers' requirements, in order to satisfy the customers and to increase their earnings. Another reason is cost where in social media with a minimum budget the company advertisements, products information can be speeded very quickly to many customers and potential ones.

Regarding Albania context it is seen that the companies' social media usage is present. All the companies have created their profiles in the social platforms. If we refer to the monitoring statistics we see that the companies, banks or universities which have more likes, share, comments are the ones with more satisfied customers. If we have a look over the marketing budget left to social media compared to traditional media it is in the lever of 5-10\%. This number seems to be small and it

\footnotetext{
1 Epoka University was established in 2008 and is owned by the "Turgut Özal" Education Institution. It is one of best national leading private research universities and in the mid-term, aims at becoming one of the top universities in the region. (Epoka University, 2015) 2 The European University of Tirana was established in 2006 from a group of young academics, journalists, and managers. It aims to be a leading university in the development of knowledge in the Albanian society; a centre of excellence in the academic formation of our students; of expertise in the social, political, legal and economic studies in the country, with a wider impact in region and beyond; as well as a center of excellence in scientific research according to the areas of expertise within the university. (UET, 2015)
} 
is, if we compare to traditional marketing however this number can be small also due to the cost which is very low compared to printing materials, outdoor advertisement or traditional media buying cost.

Companies in Albania use social media to publish advertisements, products information, company information like social events, they publish content that stimulates customer engagement, games etc. While we came to the usage of Facebook we see that in all sectors the customer engagement is related to their satisfaction. The answers from companies confirms that mainly the social media is used to publish every new product/service in order to reach to the customers and also to the friends of customers with the aim to gain them as a customer. The share effect in the Facebook makes possible the spreading of the information/ content at many other people. People have a characteristic of talking to other people.

Word of mouth and share effect besides the positive effect of spreading to many people also can have the negative effect. Social media cannot be controlled. A negative comment from any of the customers can be seen by many other people which can learn any problem occurred with your product for this reason companies shall design strategies for social media usage. They shall not create any content that can stimulate unsatisfied customers to reply or to share their experiences.

In this paper it was mostly focused on the usage of social media marketing by the companies in Albania. Future studies may be done over the effect that social media marketing have over the customer behavior and its effect in company sales.

If we have to give an opinion over the usage of social media considering the above facts we may confirm that social media has achieved its aim in field of marketing. More clicking, more satisfied customers, more earnings for the company.

\section{Bibliography}

[1] Albtelecom. (n.d.). Retrieved from http://www.albtelecom.al/en/about-us/company

[2] BKT. (2015). BKT (National Commercial Bank). Retrieved from http://www.bkt.com.al/322.aspx

[3] Bunguri, A. (2015, May 25). Corporate Communication Manager at BKT. (E. Cela, Interviewer)

[4] Chon, C. (2015, January 23). How to Properly Use Social Media to Fit Your Business Strategy. Forbes.

[5] Dkyun Lee, Kartik Hosanagar, Harikesh S.Nair. (2014, October). The Effect of Social Media Marketin on Consumer Engagement: Evidence from Facebook. Iss. The Wharton School, Stanford GSB.

[6] Donna Hoffman, Thomas Novak. (2014, November). Why Do People Use Social Media? Empirical Findings and a New Theoretical Framework for Social Media Goal Pursuit (January 17, 2012). National Science Foundation.

[7] Epoka University. (2015). Retrieved from www.Epoka.edu.al: http://epoka.edu.al/home-about-epoka-epoka-inbrief-1-1039.html

[8] Eva Markos Kujbus, Mirko Gati. (2012). Social Medias new role in Marketing Communication and its opportunities in online strategy building.

[9] Evans, D. (2010). Social Media Marketing: The Next Generation of Business Engagement. John Wiley \& Sons.

[10] Franceska Cezaroni, Domeniko Consoli. (2015). The Adoption of Use of Social Media by Micro and Small Enterprises. Conference on Social Media 2015: ECSM 2015 (pp. 65-72). Porto, Portugal: ACPI.

[11] Hamilton, S. (2011). Use of Social Media in Presidential Campaigns: Do Social Media Have an Effect on the Political Behavior of Voters Aged 18-24?" . Honors Theses. Bristol : Roger Williams University. Retrieved from http://docs.rwu.edu/cgi/viewcontent.cgi?article=1003\&context=honors_theses

[12] Hiroshi Onishi, Puneet Manchanda. (2012). Marketing Activity, Blogging and Sales. Intern. J. of Research in Marketing 29, 221-234.

[13] Howell, N. (2010, February 4). How does CRM fit with Social Media. New Media Age, pp. 28-29.

[14] Kaplan, A. M., \& Haenlein, M. (2010). Users of the world, unite! The challenges and opportunities of Social Media. Business Horizons, 59-68.

[15] Marcom. (2015, May 28). Marketing Communication Representative Albtelecom. (E. Cela, Interviewer) 
[16] McCorkindale, T. (2010). Can you see the writing on my wall? Public Relations Journal, 1-13.

[17] Ndrecka, E. (2015, June 4). Corporate Responsibility Representative Telecom Albania. (E. Cela, Interviewer)

[18] Oestreicher-Singer, Gal and Zalmanson, Lior. (2013, June 2). Content or Community? A Digital Business Strategy for Content Providers in the Social Age. MIS Quarterly Vol. 37.

[19] Parihar, M. (2012). Social Media: The Final Frontier in Customer Experience Management . 15th Nirma International Conference on Management Global Recession to Global Recovery:Opportunity, Challenges and Grouth (p. 4). Ahmedabad: Shanti Business School.

[20] Pavlik, J. V. (2001). Journalism and New Media. New York: Columbia university press.

[21] Quesenberry, K. (2015, April 18). www.socialmediatoday.com. Retrieved from Power Storytelling Social Media Marketing: http://www.socialmediatoday.com/marketing/2015-04-08/power-storytelling-social-media-marketing

[22] Raiffeisen Bank. (n.d.). Raiffeisen Bank Albania. Retrieved from https://www.raiffeisen.al/about/

[23] Raiffeisen, M. (2015, July 30). Marketing Communication Representative Raiffeisen Bank. (E. Cela, Interviewer)

[24] Robert Kozinets, K. D. (2009). Journal of Marketing.

[25] Robert Kozinets, Kristine De Valck, Andrea C. Wojnicki and Sarah J.S. (2009). Networked Narratives: Understanding Word-of-Mouth Marketing in Online Communities. Journal of Marketing, 125-140 .

[26] Stelzner, M. (2015). Social Media Marketing Industry Report. Seattle, USA: Social Media Examiner.

[27] TS, A. (2014, November 24). Linkedin. Retrieved from Guide to Using Social Media for Marketing: https://www.linkedin.com/pulse/20141124180032-100431809-guide-to-using-social-media-for-marketing

[28] Tutten, Solomon. (2014, 10 11). www.sagepub.com. Retrieved from Social Media Marketing: www.sagepub.com/sites/default/files/upm.../65654_tuten_ch1.pdf

[29] UET, U. E. (2015). Retrieved from http://www.uet.edu.al/: http://www.uet.edu.al/index.php/en/about-us/history

[30] Webometrics. (2015). Retrieved from www.webometrics.info: http://www.webometrics.info/en/europe/albania

\section{Table of Figures}

Figure 1- Telecommunication Companies Facebook Usage .....

Figure 2-Telecommunication Companies Facebook Monitoring Statistics Error! Bookmark not defined.

Figure 3-Graph of Average Likes, shares, comments per post . .72

Figure 4-Banks Facebook Usage. .72

Figure 5-Graph of Average Likes, shares, comments per post (Banks) .73

Figure 6-Universities Facebook Usage . .73

Figure 7-Graph of Average Likes, shares, comments per post (Universities) .74 